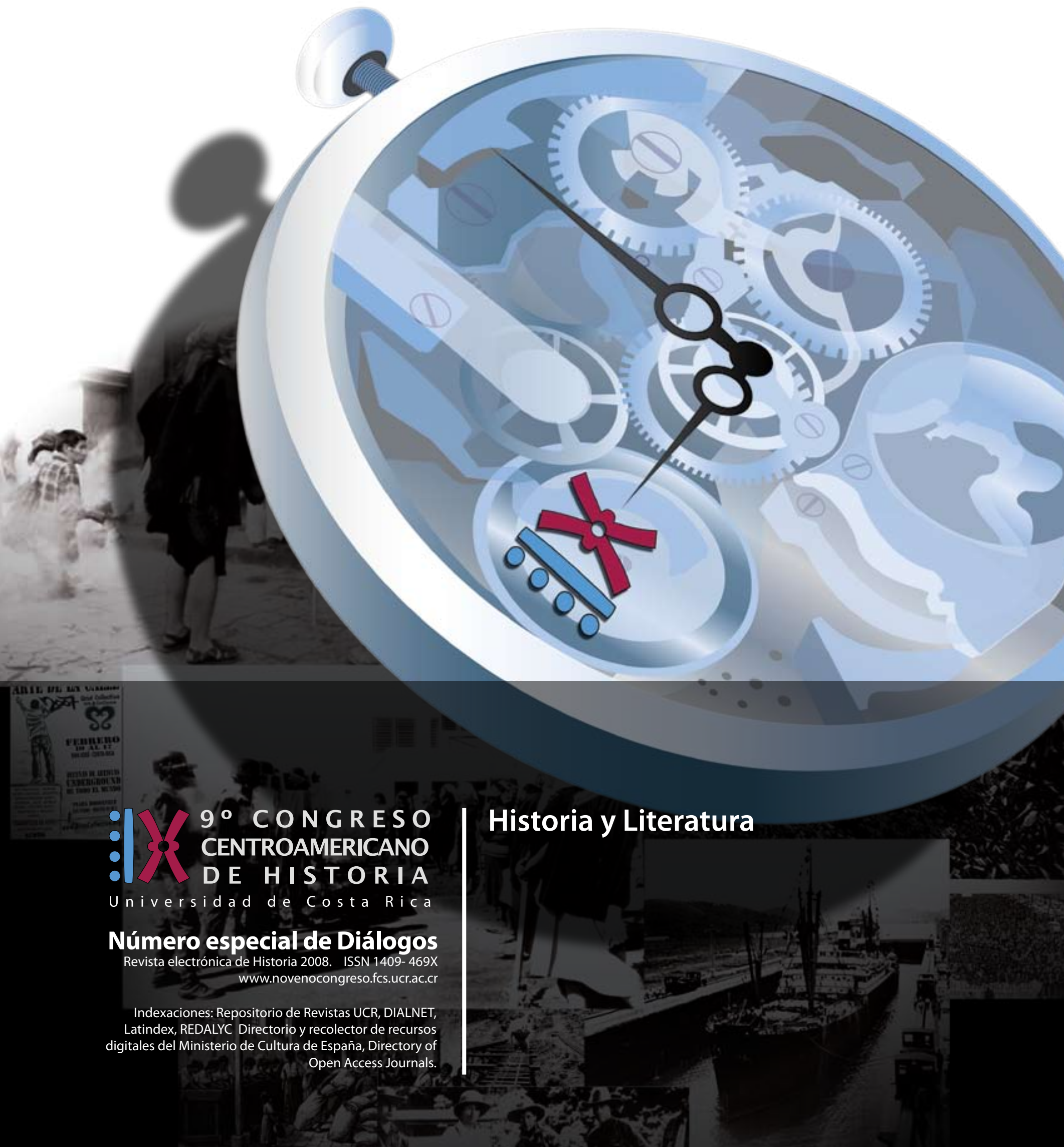




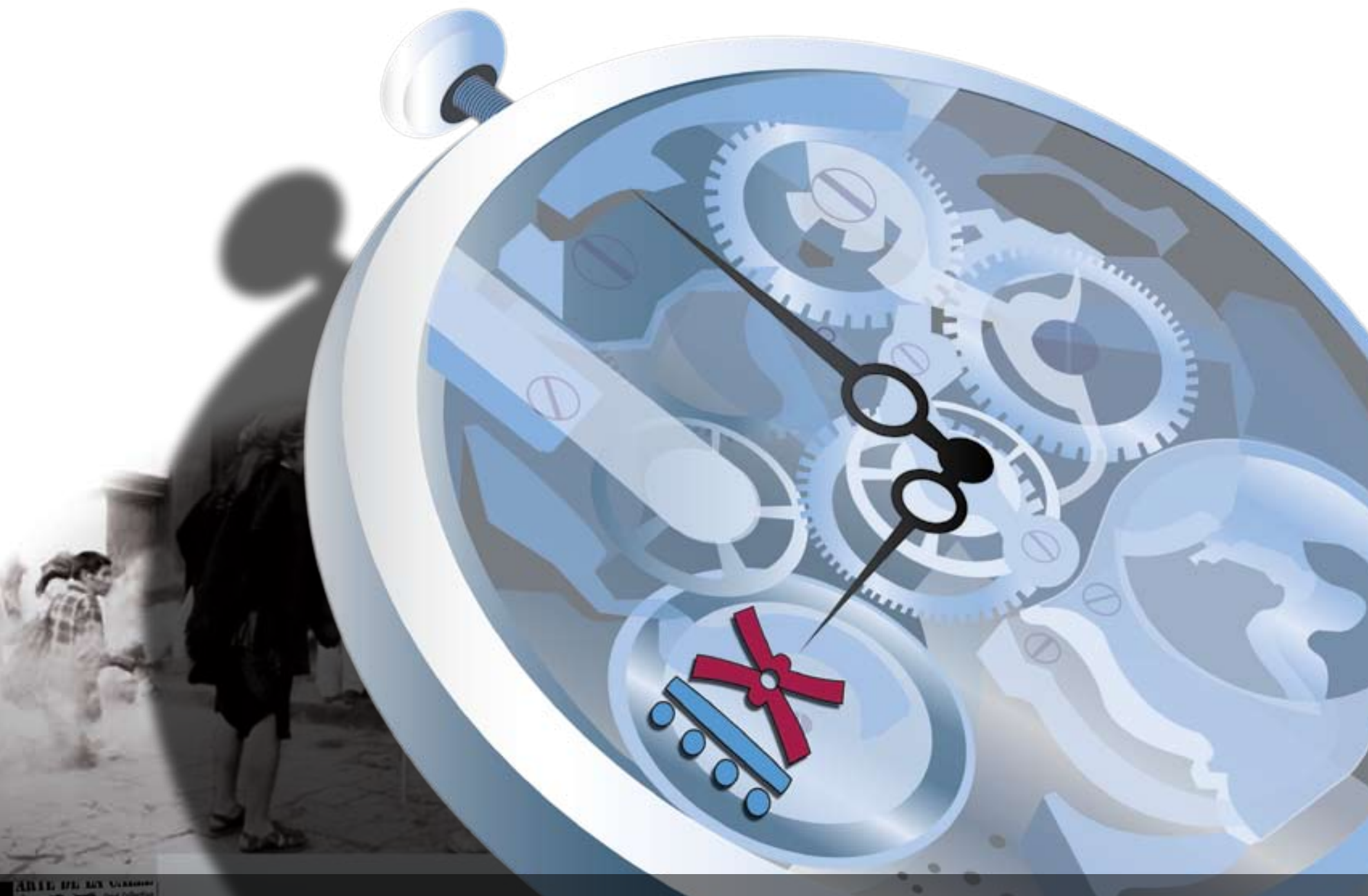

$9^{\circ}$ C O N G R E S O 2. CENTROAMERICANO DE H ISTOR I A

Universidad de Costa Rica

ISSN 1409- 469X

Fecha de recepción: 15 de mayo 2008 Fecha de aceptación: 30 de mayo 2008

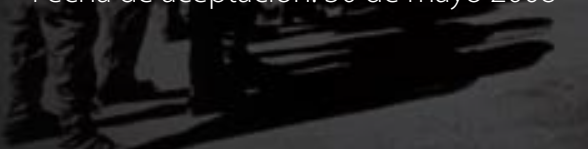

Memoria y olvido: la historia cotidiana y las esfera pública.

Los cronotopos frente al silencio en la novela EL corazón del silencio de Tatiana Lobo.

Miembros del Consejo Editorial:

Dr. Ronny Viales, Dr. Juan José Marín

Editores Técnicos:

Allan Fonseca, Andrés Cruz, Gabriela Soto

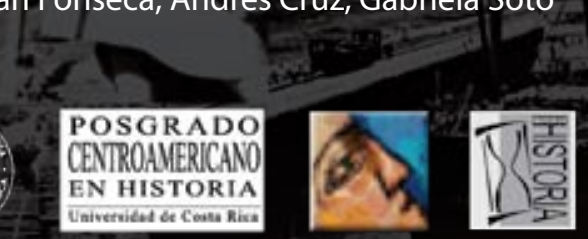


Indexaciones: Repositorio de Revistas UCR, DIALNET, Latindex, REDALYC Directorio y recolector de recursos digitales del Ministerio de Cultura de España, Directory of Open Access Journals. Diálogos Revista Electrónica de Historia ISSN 1409- 469X. Número especial 2008. Dirección web: http://historia.fcs.ucr.ac.cr/dialogos.htm

\section{Memoria y olvido: la historia cotidiana y las esfera pública. Los cronotopos frente al silencio en la novela $E L$ corazón del silencio de Tatiana Lobo.}

Adriana Sánchez González.

Estudiante de Filología Española, Universidad de Costa Rica. E-mail: adris@sulabatsu.com 


\section{Introducción.}

La novela centroamericana actual tiene varios matices distintivos. Uno de los más relevantes es, sin duda, el que se refiere a la historia. Ya no una historia de los grandes hombres y los grandes hechos, sino una historia de las historias cotidianas particulares y sus contextos familiares. En este sentido, la novela Centroamericana actual recoge diferentes tendencias analíticas que esbozan las realidades compartidas por América Latina como totalidad.

La novelística de la Memoria y el Olvido generada en nuestro continente realiza sus ejercicios narrativos a partir de distintos cronotopos $^{1}$ que cumplen el papel de colocarnos, como lectoras y lectores, frente a una realidad compuesta de retazos, que posiciona la importancia del ámbito privado dentro de la historia oficial para combatir el silencio del olvido: la gran historia es una historia que cubre el pasado. Lo tapa con un delicado mantel de encaje, como quien cubre la mesa manchada y vieja de un comedor elegante.

Ahora bien, existen varios espacios que escapan a este intento de la historia oficial por encubrir lo que no debe ser recordado: uno es la tumba vacía y el otro la cocina -experiencia cotidiana de las mujeres (guardianas por excelencia de la memoria)-; ambos se constituyen en zonas de reconstrucción de la memoria, muy importantes para nuestra realidad latinoamericana en general y centroamericana en particular, que quitan el velo a esa "historia del silencio" (colocada como una suerte de precaria protección contra un pasado que no se desea recordar, y que se convierte en la doble vejación de los muertos, olvidados una vez por las convenciones sociales en nombre del "querer ser" de nuestras sociedades y vueltos a olvidar en la fosa común vacía, despojados de identidad y enterrados en cualquier lugar del olvido colectivo).

Al nombrar al desaparecido y reconstruir -a través de la memoria familiar resguardada

1 Bajtín, Mikail. Problemas literarios y estéticos (México: Fondo de Cultura Económica, 1986) 
por las mujeres- su historia particular y su existencia olvidada, se logra rescatar del olvido colectivo no solo a una, sino las miles de violaciones de los derechos humanos perpetradas por las diversas dictaduras militares de América Latina (en este caso particular, las situaciones de los desaparecidos y sus familias). La novela que analizamos en este trabajo examina, a partir de la construcción de sus personajes, los distintos acuerdos que se establecen entre la memoria, el olvido, el silencio y el tiempo en el ámbito de la historia cotidiana, y permite hacer una revisión acerca de la pertinencia de la historia oficial y sus implicaciones actuales.

\section{La historia cotidiana y la esfera pública: los personajes de El corazón del silencio.}

Tatiana Lobo realiza un trabajo metafórico muy interesante a la hora de construir los personajes de su libro. Este ejercicio narrativo, que se ha convertido en una herramienta a la que las y los escritores recurren frecuentemente, se debe, según Beatriz Sarlo al repentino interés que el testimonio oral ha despertado en la comunidad de historiadores y que ha provocado que la "historia cotidiana" comience a tener un papel realmente relevante para la comunidad:

"Cambiaron los objetos de la historia, de la académica y de la de circulación masiva, aunque no siempre en sentidos idénticos. De un lado, la historia social y cultural desplazó su estudio hacia los márgenes de las sociedades modernas, modificando la noción de sujeto y la jerarquía de los hechos, destacando los pormenores cotidianos articulados en una poética del detalle y de lo concreto. Del otro, una línea de la historia para el mercado ya no s e limita solamente a la narración de una gesta que los historiadores habrían ocultado o pasado por alto, sino que también adopta un foco próximo a los actores y cree descubrir una verdad en la reconstrucción 
de sus vidas. "2

Este desplazamiento del interés hacia los márgenes repercute de forma directa en los estilos de las novelas actuales: la novela histórica tradicional, que versa sobre los "grandes hombres" y sus "grandes hechos" es forzada a convivir con una novela que narra los hechos cotidianos de las personas "reales". Sin embargo, este cambio no es gratuito, y en muchos casos, tiene sus motivaciones ideológicas.

El caso de El corazón del silencio es una muestra de estas motivaciones. La construcción de personajes de Tatiana Lobo para esta novela tiene dos ejes que sostienen el movimiento de la narración. En el primero, las mujeres concentran la fuerza de la historia cotidiana particular, y en el segundo, los hombres representan la esfera pública (la "gran historia") que influye sobre la historia cotidiana particular de una persona, una familia, un grupo específico. Aquí se presenta la primera estrategia narrativa de la novela: la revaloración de un espacio tan femenino como la memoria. La historia cotidiana se construye a partir de los ejercicios de memoria y las mujeres, portadoras por excelencia del saber oral, han sido a través de los siglos las guardianas de la memoria, que es la base de las historias familiares (en este sentido, podemos decir que la novela delimita uno de los roles de género más importantes de las mujeres durante los conflictos bélicos).

Pero debemos tomar en cuenta que toda historia particular está influenciada por fuerzas externas. Tal es el caso de las guerras, los desastres naturales, las dictaduras, la “esfera pública”. Los grandes hechos irrumpen irremediablemente en las historias cotidianas particulares, y producen cambios, rupturas y pérdidas en muchos casos.

2 Sarlo, Beatriz. Tiempo Pasado: Cultura de la memoria y giro subjetivo. Una discusión, (México: Siglo XXI Editores, 2006), 12. 
Una vez explicado este binomio de historia cotidiana/ esfera pública, podemos acercarnos a los personajes de la novela de Lobo para revisar sus particularidades y evidenciar el ejercicio que la autora plantea a modo de metáfora.

Hay dos grupos de personajes en la novela El corazón del silencio. El primero está compuesto por las dos mujeres que narran, desde sus perspectivas particulares y sus ejercicios de memoria, la historia familiar. El segundo está compuesto por un grupo de hombres (el sacerdote, el revolucionario, el miliciano y el desaparecido) que representan la esfera pública que irrumpe en el ámbito privado de las dos mujeres. Un tercer componente de esta construcción histórica se encuentra en el personaje de "la loca" (Melania) que se convierte en un puente entre ambos espacios y es el eje central del silencio en la novela.

Esta división de caracteres es reforzada por el escenario en el cual se desarrollan los hechos narrativos: las mujeres se encuentran permanentemente en la cocina de la casa familiar, revisando fotografías, haciendo memoria e intentando evitar que la esfera pública irrumpa con sus hechos irremediables y acabe con la paz que se ha construido alrededor del silencio. En ese sentido, podemos decir que Lobo logra mostrarnos un ejemplo de la manera en la que los hechos históricos afectan a los individuos en su privacidad y en su relación con su familia o gente cercana. Esto porque el libro nos muestra que no existe realmente una división entre lo público y lo privado, sino una fluctuación entre ambos que incide en la memoria de quien está intentando recordar. La imagen que se delinea en la novela es clara: hay solo dos personajes que interactúan y miden el tiempo a partir de esa interacción. Todos los demás personajes, que son fundamentalmente masculinos, representan el mundo histórico exterior que incide constantemente sobre el ámbito de lo privado. 


\section{Memoria, olvido, tiempo y silencio. Los componentes subjetivos.}

\section{Memoria y silencio.}

La función social de la narración se sostienen sobre la memoria. La novela pretende resguardar una memoria histórica que los libros de historia no recogen, el aspecto de la historia cotidiana y cómo esta se ve afectada por los grandes hechos. Las dos mujeres de la novela tienen sus características específicas y sus maneras de construir la historia: Yolanda, que está de regreso al mundo que abandonó antes del comienzo de la dictadura, está de vuelta para enfrentarse con su pasado y para reconciliarse con la memoria de su primo desaparecido. Aurelia, quien se quedó custodiando la memoria familiar en la casa de los abuelos, vive en una lucha constante con el tiempo y el silencio. Las dos mujeres irán desenrollando el ovillo de la historia familiar. En este ejercicio de memoria hecho por Aurelia y Yolanda, hay un agente externo que provoca ruptura en la construcción de la historia: la figura de Augusto Pinochet, que representa el fantasma de la dictadura chilena y remite a la desaparición de miles de personas durante el gobierno militar. Las dos mujeres son fuerzas que chocan sobre este eje central a partir de sus perspectivas ideológicas: Aurelia es partidaria del dictador en tanto que Yolanda reprueba la dictadura. El silencio que se genera a partir del intento de ambas mujeres por mantener la armonía de la corta visita de Yolanda a Chile se va resquebrajando conforme los recuerdos se agotan y la ausencia del primo desaparecido se hace obvia entre las mujeres. Es aquí donde el papel de Melania ("la loca de la casa") se vuelve importante. La presencia de esta mujer es inevitable en los recuerdos, y en ella se agotan todos los intentos por evadir la irrupción de la esfera pública en el ámbito privado. Aurelia, quien recibiera y ocultara el cuerpo de Marcelo - primo asesinado por los milicianos durante la dictadura- posee un trozo de esa 
memoria que pugna por reconstruirse. Yolanda, que ha estado apartada de la familia por mucho tiempo, requiere de ese pequeño pedazo de historia para completar el cuadro de la memoria que está intentando rescatar. Sin embargo, y por una especie de acuerdo tácito que Sarlo llama "silencio como prohibición"3 ambas mujeres aceptan no mencionar al desaparecido y sus recuerdos sobrevuelan alrededor de éste intentando no tocarlo.

Según Sarlo el silencio no necesariamente impide la irrupción del pasado en nuestra vida cotidiana, y pone a competir a la historia y a la memoria en la reconstrucción de los hechos vividos. La memoria se intenta perder, muchas veces, en nombre de las buenas relaciones familiares, en nombre de la tranquilidad, y en nombre del olvido. Pero la irrupción de la historia pública en el ámbito de las historias privadas hace casi imposible que el silencio forzado se pueda conservar.

\section{Tiempo.}

Los tiempos (des tiempos) alrededor de los personajes se construyen a partir del compromiso y la complicidad desde lo cotidiano. Nuestra percepción del tiempo siempre es relacional y está en relación con otras personas o con otras cosas. Tal es el caso de los fantasmas de la familia, que son parte vital del tiempo de Aurelia. Para Aurelia, el tiempo se congela con la muerte de Marcelo. Una vez que él desaparece tragado por las aguas fangosas del pantano, Aurelia comienza a recibir las visitas del pasado (fantasmas) en un acto inconsciente de negación del presente. Los fantasmas llegan de todas las épocas y se instalan en la casa de los abuelos para hacerle compañía a la única habitante actual de la casa. Este esfuerzo mental por sustraerse del dolor provocado por la muerte hace que, vista desde afuera, Aurelia sea una especie de "loca encerrada en el ático".

3 Sarlo, 7-10. 
El tiempo como abstracción no existe, y siempre lo medimos en relación con algo más.

En el caso de Yolanda, el tiempo es una especie de línea que en algún momento se corta y luego sigue su rumbo. Este tiempo lineal, se mide de acuerdo con la cantidad de horas que le restan en la visita a su prima:

“Aurelia, aliviada, caminó hasta sus libros. Sacó el mapamundi, se lo pasó a Yolanda y le pidió que localizara las rutas de sus viajes. Yolanda obedeció, contenta de recuperar su pasado inmediato que en ese momento le pareció su presente, porque el presente, con tantos cambios, se había vuelto algo muy confuso." 4

Pero el tiempo de Aurelia siempre irrumpe en el de Yolanda en la figura de un recuerdo, una fotografía, una palabra, un aroma o una memoria visual. Si bien Yolanda regresa a la casa para rellenar ese vacío en la línea temporal de su vida, el choque con las novedades del pueblo, la irrupción de memorias colectivas y los cambios drásticos que ha sufrido la casa durante su ausencia no le permiten rellenar espacios vacíos, y se ve obligada a saltar del presente a su infancia, bordeando ese pasado innombrable en el cual su primo desapareció.

\section{Olvido.}

El olvido es la contra-cara de la memoria. Pero el olvido es colectivo, se da en el ámbito de lo público, en tanto que los ejercicios de memoria tienden a darse más bien en el ámbito de lo privado. América Latina ha sido un continente del olvido durante muchos años, pues no ha existido una "memoria colectiva" que rescate del olvido todas las vejaciones sufridas en sus países. Tradicionalmente, la historia ha sido contada por los grandes vencedores, y las voces de

4 Lobo W., Tatiana. El corazón del silencio, (San José, Costa Rica: Ediciones Farben, 2004), 41. 
los vencidos han sido sepultadas en el olvido colectivo.

Es hasta hace poco más de dos década que comienza el proceso de revalorización de las fuentes testimoniales periféricas y las memorias individuales cobran importancia para la construcción de nuevas versiones de la historia oficial. Sin embargo, esta revalorización de las voces marginales ha topado con otras formas de olvido a la hora de reconstruirse. Tal es el caso del cronotopos por excelencia de nuestro continente: la tumba vacía.

"En fin, lo que quería decirle es que en esa zanja donde estuve, en ese cementerio, ya no hay nadie. Poco después volvieron, sacaron los muertos y los arrojaron al lago."

En este sentido, podemos afirmar que los desaparecidos sufren la doble vejación que implican las dos versiones del olvido: el primero, el olvido colectivo, producto del silencio y el miedo. El segundo, el olvido individualizado de la identidad, en el que, aunque la fosa común sea encontrada y abierta, no existen nombres y todos los cadáveres se mezclan en una masa amorfa y carente de identidad.

\section{Conclusiones}

La necesidad de escarbar en el pasado, de volver, persigue al ser humano durante su vida. Es por ello que el olvido es prácticamente imposible en el ámbito de lo privado. Incluso podemos afirmar que el olvido colectivo solo se da de manera artificial, inducido por amenazas y a través del miedo. El silencio, por su parte, afecta en ámbito privado como una defensa contra las diferencias ideológicas, políticas y morales. Es un silencio que se produce a partir

5 Lobo, 173. 


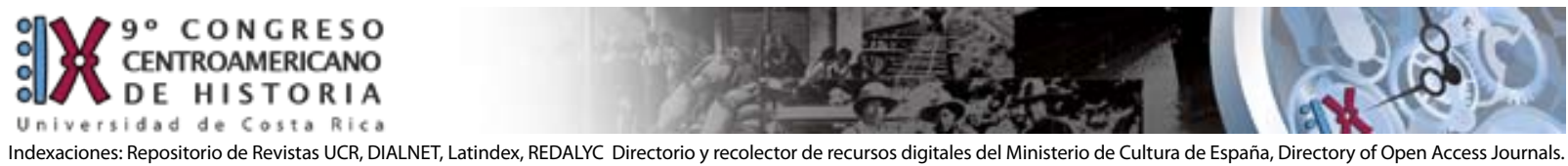

Indexaciones: Repositorio de Revistas UCR, DIALNET, Latindex, REDALYC Directorio y recolector de recursos digitales del Ministerio de Cultura de España, Directory of Open Access Journals. Diálogos Revista Electrónica de Historia ISSN 1409-469X. Número especial 2008. Dirección web: http://historia.fcs.ucr.ac.cr/dialogos.htm

del acuerdo tácito, para evitar choques y mantener las diferencias bajo control.

En la novela de Lobo se confrontan dos memorias, y esto hace posible que se tenga una visión más amplia del momento histórico particular que estas intentan reconstruir. Las personajes recuerdan relacionándose, confrontando un mismo suceso desde dos perspectivas, cada una con sus posiciones, para llegar a reconstruir un momento histórico a través de dos memorias que están situadas en lugares diferentes.

La novela está compuesta de binomios: hoy/ayer, adentro/ afuera, lo público/lo privado. De esta manera, se perfila como un intento por completar un cuadro del que estamos acostumbrados a ver solo el ámbito público sin tomar en cuenta la resonancia que éste tiene sobre lo privado. 